\title{
Ethnomedicinal and conservation status of herbs in tehsil Banda Daud Shah, District Karak, Pakistan
}

\author{
Musharaf Khan ${ }^{1}$, Abdurehman ${ }^{2}$, Farrukh Hussain ${ }^{3}$, Zabta Khan Shinwari ${ }^{4}$, \\ Shahana Musharaf ${ }^{5}$ \\ ${ }^{1}$ Department of Biology, Federal Government College Mardan, Pakistan \\ ${ }^{2}$ Department of Botany, GPGC Bannu, Pakistan \\ ${ }^{3}$ Department of Botany, Bacha Khan University, Charsadda, Pakistan \\ ${ }^{4}$ Department of Biotechnology, Quaid-i-Azam University, Islamabad, Pakistan \\ ${ }^{5}$ Department of Chemistry, Government Girls Degree College S. Malton, Mardan, Pakistan
}

\begin{abstract}
The present study documents the ethnomedicinal and conservation status of 91 herbs belonging to 81 genera and 66 families in tehsil Banda Daud Shah during 2012-2013. The information about conservation and ethnobotanical was collected through questioners and personal interviews during fieldwork using the IUCN 2001, Red Data List Categories and Criteria. Among these 36 species were found to be rare, vulnerable (30 species), infrequent (13 species), endangered ( 8 species) and dominant (4 species). From the present investigation we concluded that most plant species are going to become endangered because the natural vegetation area was change into urbanization.
\end{abstract}

Keywords: Medicinal herbs; Conservation; Banda Daud Shah; Pakistan

\section{INTRODUCTION}

The Banda Daud Shah is situated at $32^{\circ} 47$ to $32^{\circ} 048$ North and $70^{\circ} 30$ to $70^{\circ} 40$ East. The area is bounded by District Hangu on the North West, District Kohat on the North East, Tehsil Karak on the South, and Tribal area Adjoining Bannu District on the South West (Figure 1). Physiography of the area is uneven and can be divided into mountainous area, the plain and the small hillocks. The soil is generaly clayey or sandy. The fertile loamy soil is very rarely found. Although the hills are very dry, but it is a fact that it contains precious minerals like salt, gypsum and gas etc. The salt quarries are mostly at Jatta Ismail Khel and Bahader Khel, where the hills present great amount of exposed rocks salt. There is shortage of drinking water, so the people bring water from remote area. The Rainfall is scanty in the area. The area is very hot in summer and very cold in winter (Khan 2003). The climate and weathers are also influenced by wind. In summer the wind direction is variable. In July wind comes from Eastern side, carrying clouds and rainfall with them. 


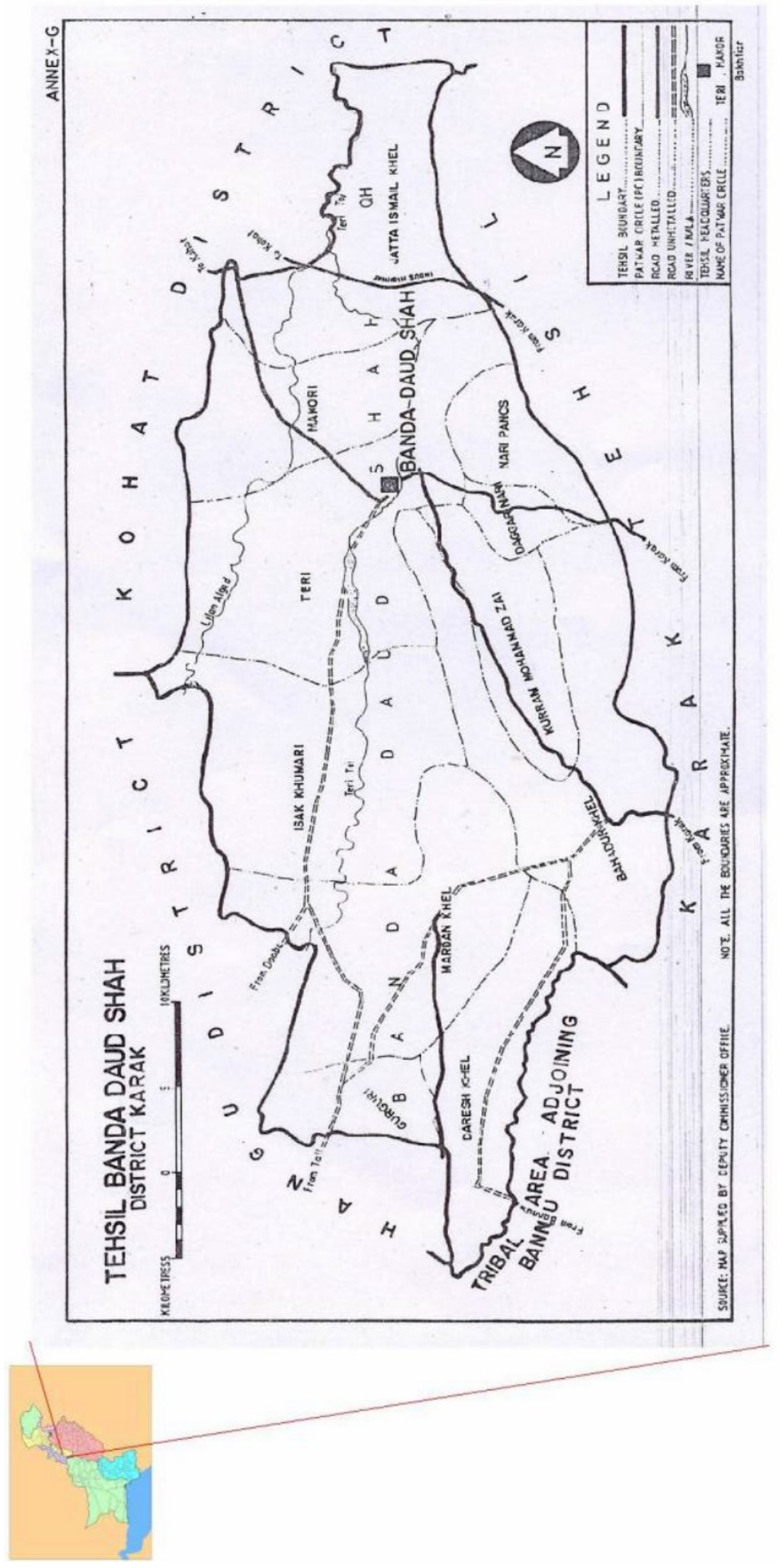

Figure 1. Map of research area. 
In hottest months, especially in June whirl winds are developed on plain area after noon due to heating and convectional uprising. Sometimes strong, dry and hot winds with huge dust enter the area from different sides. Most of the winter season is calm but at approach of February high velocity winds blow in the area. In winter season breeze from Hangu side also blows down the area for weeks together, making the winter even colder. Due to much interest in the field of plant taxanomy the area of Tehsil Banda Daud Shah was selected, so as to evaluate and documentise its flora to same extant.

The conservation status of organisms indicates the feature of plant species in the area. Conservation status of a species depends upon many factors like fuel demand, farming land, grazing, deforestation, reproduction rates and known threats. It is estimated that some 270,000-425,000 vascular plant species are already known (Govaerts, 2001). Based on the sample of species that have been evaluated through 2006, the percentage of endangered species as 40 percent of all organisms has calculated by the International Union for Conservation of Nature (IUCN) (Anon., 2008). Alam and Ali (2009) classified Astragalus gilgitensis as a Critically Endangered (CR). According to Khan et al., (2011a) 4 flowering plant species are threatened. Khan et al., (2012a) reported one specie as threatened plant from Tehsil Takht-e-Nasrati, District Karak, Pakistan. According Khan et al., (2013a) that habitat loss and removal, preface of alien species, pollution and diseases, over-exploitation and climate change are some threats facing by plants which are an important part of our ecosystem. Plant biodiversity is also under tremendous pressure due to its population explosion, unplanned urbanization, deforestation and over-exploitation of natural resources (Khan et al., 2013b). Unfortunately, very little work has been done on threatened plants of Pakistan and extremely limited information is available on this subject (Khan 2013).

Khan and Husssain (2013a) reported 7 shrubs and trees as threatened species form Takht-e-Nasratti Pakistan. These studies are principally based on IUCN criteria and with support of quantitative data. In contrast, the recent red list of IUCN (Anon., 2008) only 19 flowering plants species has been listed from Pakistan. Regarding Pakistan, previous workers have classified the plant species as threatened or rare on the basis of literature or herbarium specimen. Less work has been done according to IUCN red list categories or criteria (Khan 2013). The research area has rich biodiversity consisting of a different type of plants, some of which are used for their medicinal value. Ethnobotanical studies in various areas of Pakistan have been carried out ( Shinwari and Khan, 2000; Shinwari and Gilani, 2003; Hussain, et al. 2006; Shinwari, 2010; Murad et al., 2011; Khan et al., 2011a, 2012c, 2013c). The present research was aimed to collect, document and compile diverse and disperse traditional local information of century's experienced therapeutic uses of medicinal plants and conservation status of trees and shrubs of Tehsil Banda Daud Shah. Such a study will provide evidence for their authenticity in a particular disease and hence it will give a very interesting and rewarding prepharmacological ground for undertaking its investigation on scientific basis.

\section{MATERIALS AND METHODS}

The study was conducted by frequently surveying in winter, spring and summer during 2012 to 2013. The area is divided into plain and mountain. Habit, habitat, altitudinal range, population size, distribution range, impacts of multiple threats like habitat destruction, erosion, fuel wood cutting, grazing, poultry farms and invasive species have been studied for two years in the habitat. Plant specimens were collected from different parts of research area. Nature of habitat was analysed by soil erosion, invasive species and impacts of anthropogenic 
activities. Information on demographic (age, gender), ethnomedicinal and conservation status was gathered from each site by using a semi-structured questionnaires using stantard method Khan, (2013). During survey personal observation was also recorded. Analysis of data was made with the help of group discussions and questioners among different age classes of tehsil banda daud shah that include both genders of the society. The data was classified, tabulated, analyzed and concluded for final report.

\section{RESULT}

In the present study the ethnomedicinal and conservation status of plant species were determined in Tehsil Banda Daud shah. Total 91 species belonging to 81 genera and 36 families were found.

The Asteraceae with 12 species, Poaceae with 10 species, Amaranthaceae with 7 species, Papilionaceae with 6 species. Brassicaceae, Convolvulaceae, Lamiaceae and Solanaceae with 4 species. Boraginaceae, Chenopodiaceae, Euphorbiaceae, Malvaceae and Zygophyllaceae with 3 species. Cyperaceae and Plantaginaceae have 2 species. Aizoaceae, Aloaceae, Apiaceae, Asparagaceae, Asphodelaceae, Capparidiaceae, Caryophylaceae, Cucurbitaceae, Fumaraceae, Geraniaceae, Hypericaceae, Nyctaginaceae, Orobanchaceae, Oxalidaceae, Pedaliaceae, Polygonaceae, Primulaceae, Ranunculaceae, Scrophulariaceae, Tiliaceae and Verbenaceae with single specie (Figure 2).

The plants were divided on the basis of conservation into five classes i.e. endangered, vulnerable, rare, infrequent and dominant. In the present report, 36 species were found to be rare, Infrequent (13 species), vulnerable (30 Species) endangered (8 Species) and 4 species were dominant ( Figure 3; Table 1).

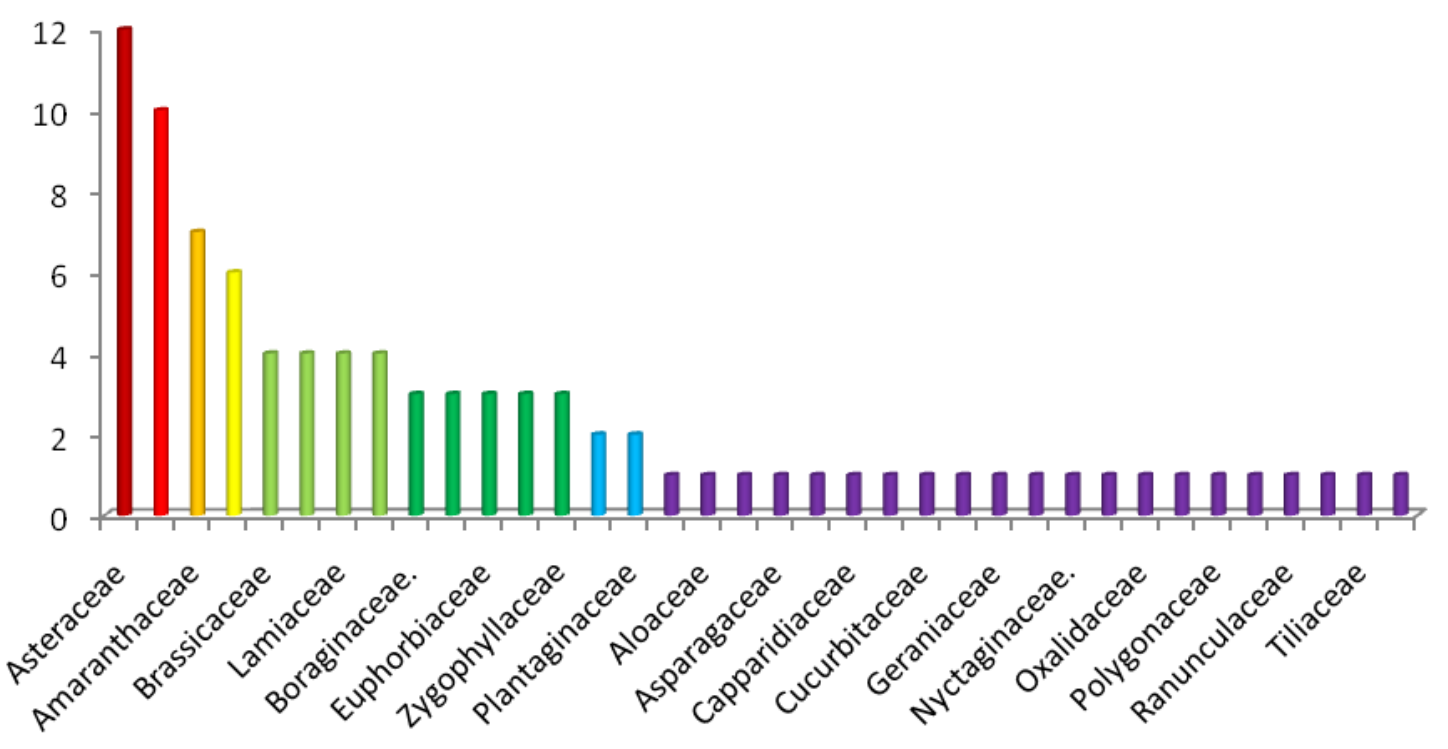

Figure 2. Family in research area. 


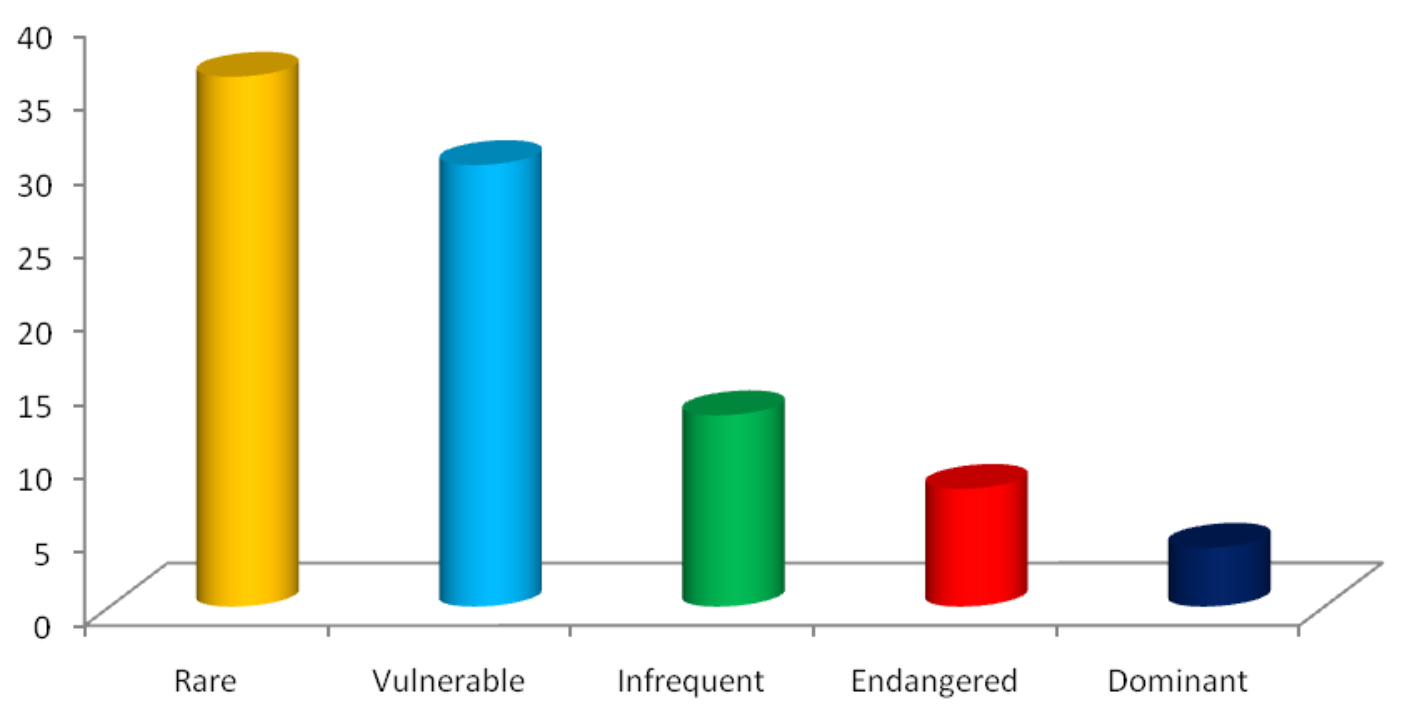

Figure 3. Conservation stutus of plant species in research area.

\section{DISCUSSION}

The study was disging to explore the anthropogenic activity and conservation activity of area. The work may be considered as bird's eye view as the information collected and described over here are no doubtly few but without them the botanical aspect of the area remains incomplete. The work will surely provide much help to future workers trying in this field in this area. The area consists of both hills and plains, much different in floristic composition. Due to lack of irrigation facilities the flora, particularly cultivated flora has much difference from highly irrigated areas of Khyber Pakhton Khawa (Khan et al., 2011). No fruit orchards have been seen in the research area. On hills different grasses, Monotheca buxifolia, Acacia modesta, Cotoneaster sps, Rzhazia stricta and Dodonaea viscosa etc are found. From the present investigation it is noticed that each species have limited to a slim distribution range and specific habitat. With the changes in environment the plant species habitat are disturbed. A vast extent road structure, stone mine, oil and gas reservires are the main cause of interruption and demolition in the habitat of plant in the area. Erosion was causing a severe damage during rains, individuals of plants species growing in sandy and river bank were found more prone to erosion than the plants found on rocky slopes and cliffs. Our observations were agreed with the workers (Khan et al., 2011; Khan and Hussain, 2013). They reported the species from almost similar habitats from other tehsils of district.

The current study was conducted, according to the IUCN red list categories and criteria (Anon., 2001), which describes in detail that if population size is fewer than 250 mature individuals with a continuous decline in their number along with no sub-populations, making the tree species eligible to be placed under Critically Endangered (CR) category. According to Khan and Hussain (2012) population size is often affected by dry periods during the growing season, when plants may not produce any viable seed and there will be no natural recruitment. No natural conscription was observed in Acacia modesta Wall and Dodonea viscosa L. Hence, it is concluded that the population sizes of rare trees and shrubs are 
constantly falling at an alarming rate, without having natural conscription. According to (Engler, 2008; Khan et al., 2012b) over-exploitation of plant species for fuel wood and fodder purpose by local communities and migrants is a complex problem and a major cause of plant extinction. Rabinowitz (1981) suggests that those species which are found over a wide geographic range but are consistently rare throughout their distribution need immediate attention. According to Davis et al., (1995), no accurate information has been published about the impacts of unsustainable use of plant species. Grazing is ecological problem observed, more in hilly area than plain area, to change the habitat of native flora. According to Khan and Hussain (2012b) force of grazing ranges from almost invisible elimination of plant material to harsh reduction of vegetational wealth and extensive erosion. From the conservation point of view, endangered species were reported from a few localities in the research area. Hence, urgent conservation steps should be taken to avoid its elimination from research area.

The plant species are the main source of medicine and other requirements of the local communities. The plants are not used properly because of the shortage of trained manpower and resources. It was noted that elder people had more knowledge about the folk uses of medicinal plants than younger generation. Most of the plants used by the local people are not conserved but are over exploited. The present study indicated that the leaves and fruit are common used against different diseases. Similar finding were also reported from other areas of Pakistan (Hussain, et al., 2006; Shinwari et al., 2006; Shinwari, 2010; Khan et al., 2011a,b, $2012,2013 \mathrm{~b}, \mathrm{c})$. Therefore it is an urgent need of conserving these plants that in future, the coming generations could be benefited from these precious plants that are a real gift of nature for the mankind.

\section{CONCLUSION}

The present study shows that the people of the area possessing good knowledge of herbal remedy but as people are going to modernization; their knowledge of traditional uses of plants may be lost. The investigated area has a rich diversity of medicinal plants and provides a conductive habitat and ideal conditions for their growth. It is necessary to stop the selling of whole trees and smuggling to other district. Alternate environmentally friendly and sustainable jobs should be provided for the local inhabitants for maintaining their living properly.

\section{Acknowledgements}

Authors are grateful to the local people of area, who have revealed the precious information about ethnomedicinal and conservation status of plant species. 


\section{References}

[1] Alam J., Ali S. L., Phyton 48(2) (2009) 211-223.

[2] Anonymous (2001). IUCN Red List Categories: Version 3.1. Species Survival Commission. IUCN, Gland, Switzerland and Cambridge, UK.

[3] Anonymous (2008). Balochistan fisheries development studies: Options for Balochistan coastal fisheries and aquaculture. In: Competitiveness support fund. p. 17

[4] Anonymous (2008). IUCN Red List of threatened species, www.iucnredlist.org cited on December 27th 2009.

[5] Davis S.D., Heywood V.H., Hamilton A.C. (1995). Centres of Plant Diversity: a guide and strategy for their conservation, Vol. 2 (Asia, Australasia and the Pacific). Cambridge: IUCN.

[6] Engler M., Traffic Bulletin 22(1) (2008) 4-5.

[7] Govaerts R., Taxon 50(4) (2001) 1085-1090.

[8] Hussain F., Badshah .L, Dastigar G., Pak. J. Pl. Sci. 12 (2006) 27-40.

[9] Khan M. and F. Hussain (b), African Journal of Agricultural Research 7(44) (2012) 5858-5872.

[10] Khan M., F. Hussain, International Journal of Biodiversity and Conservation 5(1) (2013) 20-26.

[11] Khan M., F. Hussain, S. Musharaf (a), Journal of Biodiversity and Environmental Sciences 2(3) (2012) 48-56.

[12] Khan M., F. Hussain, S. Musharaf (a), International Journal of Biodiversity and Conservation 5(1) (2013) 39-46.

[13] Khan M., F. Hussain, S. Musharaf (b), Annual Review and Research in Biology 3(1) (2013) 31-41.

[14] Khan M., F. Hussain, S. Musharaf (c), Journal of Medicinal Plant Research 7(22) (2013) 1636-1651.

[15] Khan M., F. Hussain, S. Musharaf (b), International Journal of Biosciences 2(3) (2012) 67-74.

[16] Khan M., Z. K. Shinwari, S. Musharaf (a)., Journal of Biodiversity and Environmental Sciences 1(6) (2011) 155-164.

[17] Khan M. (2013). Dimension and composition of plant life in Tehsil Takht-e-Nasrati, District Karak, Khyber Pakhtunkhawa, Pakistan. PhD. Thesis (Plant Ecology), Department of Botany, University of Peshawar, Peshawar, Pakistan.

[18] Khan M., F. Hussain, S. Musharaf, International Journal of Biosciences 1(3) (2011) 45-50.

[19] Khan M., S. Musharaf, Z. K. Shinwari (b). Research In Pharmaceutical Biotechnology 3(4) (2011) 46-52.

[20] Murad W., Ahmad A., Gilani S. A. Khan M. A., Journal of Medicinal Plants Research 5(7) (2011) 1072-1086. 
[21] Rabinowitz D. (1981). Seven forms of rarity. In: The Biological Aspects of Rare Plant Conservation. (Ed.): H. Synge. Wiley and Sons Ltd. 205-217.

[22] Shenji P. (1994). Himalayan Biodiversity Conservation Strategies. Himavikes Pub. No. 3.

[23] Shinwari M. I., Khan M. A., J. thnopharmacol. 69 (2000) 45-56.

[24] Shinwari Z. K., J. Med. Pl Res. 4 (2010) 161-176.

[25] Shinwari Z. K., Gilani S. S., J. Ethnopharmacol, 84 (2003) 289-298. 